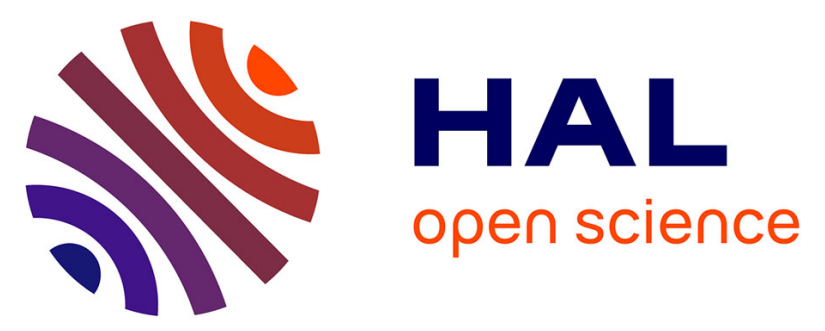

\title{
Early recurrent arrhythmias after out-of-hospital cardiac arrest associated with obstructive coronary artery disease: Analysis of the PROCAT registry
}

Hugo Bellut, Lucie Guillemet, Wulfran Bougouin, Julien Charpentier, Omar Ben Hadj Salem, Jean-François Llitjos, Marine Paul, Sandrine Valade, Shirley Spagnolo, Lionel Lamhaut, et al.

\section{To cite this version:}

Hugo Bellut, Lucie Guillemet, Wulfran Bougouin, Julien Charpentier, Omar Ben Hadj Salem, et al.. Early recurrent arrhythmias after out-of-hospital cardiac arrest associated with obstructive coronary artery disease: Analysis of the PROCAT registry. Resuscitation, 2019, 141, pp.81 - 87. 10.1016/j.resuscitation.2019.05.034 . hal-03486865

\section{HAL Id: hal-03486865 https://hal.science/hal-03486865}

Submitted on 20 Dec 2021

HAL is a multi-disciplinary open access archive for the deposit and dissemination of scientific research documents, whether they are published or not. The documents may come from teaching and research institutions in France or abroad, or from public or private research centers.
L'archive ouverte pluridisciplinaire HAL, est destinée au dépôt et à la diffusion de documents scientifiques de niveau recherche, publiés ou non, émanant des établissements d'enseignement et de recherche français ou étrangers, des laboratoires publics ou privés.

\section{(ㄷ)(1) $\$$}

Distributed under a Creative Commons Attribution - NonCommerciall 4.0 International 


\section{Early recurrent arrhythmias after out-of-hospital cardiac arrest \\ 2 \\ 3}

4

1. Medical Intensive Care Unit, Cochin Hospital (APHP), Paris, France

2. Paris Descartes University, Sorbonne Paris Cité-Medical School, Paris, France

3. Cardiology Department, European Georges Pompidou Hospital (APHP), Paris, France

4. Cardiology Department, Cochin Hospital (APHP), Paris, France

5. Emergency Department, Cochin Hospital (APHP), Paris, France

6. SAMU 75, Necker Hospital (APHP), Paris, France

7. INSERM U970 (team 4), Paris Cardiovascular Research Centre, Paris, France

\section{Corresponding author}

Lucie Guillemet, Medical Intensive Care Unit, Cochin Hospital (APHP), Paris, France luceguillemet@hotmail.com

\section{Funding}

The PROCAT registry is financially supported by a grant from the French Ministry of Health (CRC BDD 2017)

Word counts: Abstract: 275/ Text: 2771 (3 Tables and 1 Figure)

\section{Disclosures}

The authors have reported that they have no relationships relevant to the contents of this manuscript to disclose. 
Abstract (275 words)

\section{Objective}

After out-of-hospital cardiac arrest (OHCA) associated with obstructive coronary artery disease (CAD), the risk of recurrence during the early period is unclear and the indication for anti-arrhythmic treatment is debated. We assessed the incidence and predisposing factors for severe cardiac arrhythmias in this population.

\section{Design}

Retrospective study in a cardiac arrest centre.

\section{Settings}

The primary endpoint was the occurrence of major cardiac arrhythmias from hospital admission to intensive care unit (ICU) discharge in patients admitted after an OHCA associated with obstructive CAD. A major arrhythmia was defined as any arrhythmic event (auricular or ventricular) associated with cardiac arrest recurrence and/or severe arterial hypotension. Secondary outcomes were time from ICU admission to arrhythmia occurrence and all-cause in-ICU mortality. Risk factors for recurrence of a major arrhythmia were assessed using multivariate analysis.

\section{Patients}

We included all consecutive OHCA patients resuscitated from ventricular fibrillation (VF) or pulseless ventricular tachycardia (VT) as initial rhythm associated with obstructive $\mathrm{CAD}$, and who had a successful primary percutaneous coronary intervention.

\section{Intervention}

None

\section{Measurements and Main Results}

Among 256 patients, a major arrhythmia occurred in 29 (11.3\%), within the first 24 hours in $79.3 \%$ of cases and were mostly VF (44.8\%). Mortality rate was significantly increased in patients with major arrhythmia recurrence (69\% vs $41 \%$; $\mathrm{p}=0.006$ ). Factor significantly associated with recurrence of severe arrhythmia was male gender (OR 0.32 [0.12-0.92]; $\mathrm{p}=0.034)$. Treatment with prophylactic antiarrhythmic in the ICU was not associated with a change in the risk of recurrence (OR 0.85 [0.21-3.65], $\mathrm{p}=0.82$ ).

\section{Conclusion}

An early recurrence of major arrhythmia was observed in more than $10 \%$ of post-cardiac arrest patients. These events happened mostly within the first 24 hours. The interest of prophylactic antiarrhythmic treatment remains to be evaluated in this population.

Key word: cardiac arrest; acute coronary syndrome; arrhythmia recurrence; prophylaxis anti arrhythmic treatment. 


\section{Abbreviations}

72

$73 \quad$ AA $=$ anti-arrhythmic

$74 \quad$ ACS $=$ acute coronary syndrome

$75 \quad$ AMI $=$ acute myocardial infarction

$76 \quad$ BLS $=$ basic life support

$77 \mathrm{CA}=$ cardiac arrest

$78 \mathrm{CAD}=$ coronary artery disease

$79 \quad \mathrm{ECG}=$ electrocardiographic

$80 \quad \mathrm{ICU}=$ intensive care unit

$81 \mathrm{LVEF}=$ left ventricular ejection fraction

$82 \quad \mathrm{OHCA}=$ out of hospital cardiac arrest

$83 \mathrm{OR}=$ odds ratio

$84 \quad \mathrm{PCI}=$ percutaneous coronary intervention

85 PROCAT $=$ Parisian region out of hospital cardiac arrest

$86 \mathrm{ROSC}=$ return of spontaneous circulation

$87 \quad$ TIMI $=$ thrombolysis in myocardial infarction

$88 \quad \mathrm{VF}=$ ventricular fibrillation

$89 \quad \mathrm{VT}=$ ventricular tachycardia

90 


\section{Introduction}

Sudden cardiac death is an important public health issue, with an estimated incidence attributable to ventricular fibrillation (VF) among adults in Europe of 14 per 100,000 person years [1]. Although survival is higher in these VF patients as compared with other causes of cardiac arrest (CA), many of these patients will die during the post-resuscitation period [2].

While early recurrence of VF after return of spontaneous circulation (ROSC) and during transportation is frequent [3] and is subjected to international recommendations [4], data regarding incidence and management of recurrent arrhythmia in the next hours and days are scarce. It is unknown if early coronary reperfusion in CA due to an acute coronary syndrome (ACS) is sufficient to prevent from recurrence of arrhythmia. Contrary to acute myocardial infarction (AMI), in which this has been extensively evaluated $(5,6)$, indication for prophylactic anti-arrhythmic (AA) treatments during the post-resuscitation period is unclear.

In the present study, we hypothesized that arrhythmia recurrences might be a frequent event and that it would be useful to identify risk factors. Therefore, we aimed to evaluate the incidence of in-ICU severe arrhythmia in patients resuscitated from a VF or pulseless ventricular tachycardia (VT) associated with obstructive coronary artery disease (CAD) and who were treated with early percutaneous coronary intervention (PCI). We also aimed to identify risk factors for developing arrhythmia during the post-resuscitation period.

\section{Materials and methods}

\section{Study setting:}

We performed a single center study between January 2007 and December 2016 in the 24-bed medical ICU at Cochin University Hospital (Paris, France). We included all consecutive patients with an initial $\mathrm{VF} / \mathrm{VT}$ associated with obstructive CAD and who were successfully treated with early percutaneous coronary intervention (PCI). Patients with reperfusion failure and patients who died before ICU admission were not included in the analysis.

Patients' data were prospectively entered in the PROCAT (Parisian Region Out of Hospital Cardiac ArresT) electronic registry database that was previously described [7], according to Utstein style [8]. The following information was recorded prospectively for each patient: demographic data, clinical parameters, cardiac arrest location, initial cardiac rhythm, time from collapse to basic life support (BLS) and time from BLS to sustainable return of spontaneous circulation (ROSC), BLS provided by witness, CPR management, coronary angiogram data, temperature management over the first 48 hours, 
use of prophylactic anti-arrhythmic (AA) treatments, need for epinephrine or dobutamine, occurrence and type of severe arrhythmia and ICU mortality.

The Cochin CA registry (PROCAT) was approved by our local ethics committee (Commission d'Ethique de la Société de Réanimation de Langue Française ; and Comite Consultatif sur le Traitement de l'Information en matière de Recherche dans le domaine de la Santé \#CNIL_91239, \#CCTIRS_12-336, \#CE_SRLF_11-353). According to French law, our institutional review board waived the need for written informed consent.

\section{Post cardiac arrest management:}

As part of our local policy [9], immediate coronary angiogram was considered in all patients with a possible cardiac cause of arrest, regardless to electrocardiographic changes. After resuscitation, patients were admitted directly to the catheterization laboratory, before intensive care admission, and a PCI was attempted if a significant acute coronary lesion possibly responsible for the cardiac arrest was identified. A coronary lesion was considered as a culprit lesion if unstable and resulting in more than a $50 \%$ reduction in luminal diameter by visual estimation [7]. Patients with a TIMI 3 score flow were considered to have a successful revascularization, as compared with all other patients with a TIMI score flow rated 0,1 or 2 [10]. Targeted temperature management using external cooling and targeting $33^{\circ} \mathrm{C}$ was started as soon as possible and was maintained during 24 hours. At time of ICU admission, the decision to introduce any prophylactic AA treatment was left to the discretion of the physician in charge. Post-resuscitation shock was defined as the need for continuous epinephrine, norepinephrine or dobutamine infusion to maintain mean arterial pressure above $60 \mathrm{mmHg}$ for more than 6 hours despite adequate fluid loading.

\section{Outcome assessment:}

The primary endpoint was the occurrence of major arrhythmia during the ICU stay. Arrhythmia could be either auricular or ventricular but had to provoke either a cardiac arrest recurrence or a severe arterial hypotension requiring catecholamine introduction (or an increase if previously used). In addition, a sensitivity analysis was performed by restricting the primary outcome to severe ventricular arrhythmia recurrences (VF, pulseless VT).

Secondary outcomes were time from ICU admission to arrhythmia occurrence, clinical consequence, all causes mortality and management of this arrhythmia. 
160 Descriptive statistics were reported as median (with interquartile range) and frequency (percentage) 161 for continuous and categorical variables respectively. Characteristics of the 2 subgroups (with and 162 without major arrhythmia occurrence) were compared using the Chi-square test or the Fisher's exact 163 test.

164 Variables associated with the occurrence of a major arrhythmia with a p-value $<0.20$ in the univariate 165 test were included in the multivariate analysis. The logistic regression predicting the occurrence of a 166 major arrhythmia integrates the following variables: age, sex, arterial hypertension, smoking, place of 167 the CA, number of defibrillation attempts, administration of prophylactic AA drugs and initial lactate 168 value. In a sensitivity analysis, we re-runed the model restricting the endpoint to severe ventricular 169 arrhythmias.

170 All statistical tests were two-sided using a type I error of 0.05 . Analyses were performed using 171 STATA/SE 14.2 (college station, TX, USA).

\section{Results}

Between January 2007 and December 2016, 392 consecutive patients had an immediate coronary angiogram performed as soon as possible after an OHCA with an initially shockable rhythm. Among them, 256 patients (65.3\%) with significant acute coronary lesion_were treated with successful PCI and were then transported in the ICU. Patients with no significant coronary artery lesion, patients with an ACS not revascularized and patients who died before ICU admission were not retained in the analysis (Figure 1).

\section{Patients}

Baseline characteristics of the whole population are described in Table 1. Patients were mostly male with a median age of 59 y.o. Cardiac arrest was witnessed in $97 \%$ of cases and bystanders provided CPR in $72 \%$. An automated external defibrillation delivered at least two shocks in 117 (46\%) patients and $104(41 \%)$ patients received amiodarone during the CPR sequence. Only $40 \%$ of patients had an ST-segment elevation on post-resuscitation ECG and a quarter of them had a triple-vessel coronary disease (Table 2). More than $90 \%$ of the patients had a successful PCI, as assessed by a TIMI 3 score (Thrombolysis In Myocardial Infarction [10]) flow. Therapeutic hypothermia was performed in 90\% of patients over the first 24 hours. A post-resuscitation shock occurred in 133 patients (52\%). There were significantly more patients with a low left ventricular dysfunction (LVEF <50\%) in the major arrhythmia recurrence group as compared with controls $(83 \%$ vs $64 \% ; p=0.03)$. 
193 A major arrhythmia was observed in $29(11.3 \%)$ patients. As compared with controls, there were 194 significantly more smoking patients (70\% versus $89 \%$; $=0.04$, respectively) and cardiac arrest 195 occurred less frequently in a public place in the major arrhythmia group ( $51 \%$ versus $24 \%$; $\mathrm{p}=0.006$ ).

196 During the first 48 hours in ICU, there was no significant difference regarding the median lowest 197 temperature between the two groups. Regarding the management of the post-resuscitation shock, 198 dobutamine and/or epinephrine were used in the same proportion of patients in the 2 groups (55\% vs $19966 \%, \mathrm{p}=0.33)$.

200

201

202

203

204

205

206

207

In the whole population, all cause ICU mortality was $44.5 \%(\mathrm{n}=114)$ and 3 patients (1\%) died of a major arrhythmia recurrence. Mortality was significantly higher in the major arrhythmia recurrence group $(69 \%$ vs $41 \%$; $\mathrm{p}=0.006)$.

In the group of patients with recurrence of a major arrhythmia, this arrhythmia was a VF in 13 (44.8\%) patients, a non-perfusing VT in 10 (34.5\%), an atrial fibrillation in 4 (13.8\%) and a polymorphic VT in 2 (6.8\%). Median time from ICU admission to major arrhythmia occurrence was 16 hours (0.33-336). In $79.3 \%$ of cases, major arrhythmia occurred within the first 24 hours after the ROSC. Regarding potential causes of arrhythmia, a stent thrombosis was confirmed in 4 cases (13.8\%) and hypokalemia in 2 cases (6.9\%). Apart from the initial ACS, no additional cause of arrhythmia was identified in the other patients.

\section{Prophylactic anti-arrhythmic treatment}

In the whole population, $36(14 \%)$ patients received a prophylactic AA treatment at admission in the ICU (which was amiodarone in all cases), with no significant difference between the 2 groups (4/29 in the major arrhythmia group vs 32/227 in controls; $p=1$ ) (Table 1).

\section{Management of recurrent arrhythmia}

For management of recurrent severe arrhythmia, 17 of $29(58.6 \%)$ patients received at least one defibrillation. Other therapies administered were amiodarone, magnesium bolus, lidocaine and potassium infusion for $16(55.2 \%), 8$ (27.6\%), 3 (10.3\%) and $3(10.3 \%)$ patients respectively.

\section{Risk factors of major arrhythmia}

In multivariate analysis, factor significantly associated with recurrence of severe arrhythmia was male gender (OR 0.32 [0.12-0.92]; p=0.034) (Table 3). Prophylactic AA treatment was not associated with 
a lesser risk of arrhythmia recurrence (OR $0.85(0.21-3.65), \mathrm{p}=0.82)$. These results were not modified by performing a sensitivity analysis using only serious ventricular arrhythmia recurrences as the primary endpoint (Supplemental table 1).

\section{Discussion}

The present study aimed to evaluate the prevalence and risk factors associated with major arrhythmia recurrence in patients resuscitated from a cardiac arrest associated with obstructive CAD. An early recurrence of major arrhythmia was observed in more than $10 \%$ of post-cardiac arrest patients. These events happened mostly within the first 24 hours.

The cause of ventricular arrhythmia during and after acute myocardial ischemia is incompletely understood but is supposed to result from both ischemia-induced electrophysiological changes and genetic factors [11]. Early coronary revascularization may decrease the incidence of recurrent arrhythmia due to ischemic lesions, but persistent ischemia-reperfusion injuries may increase the risk. Moreover, reperfusion by percutaneous coronary intervention can be incomplete [10] or can leave distal ischemic lesions not accessible to angioplasty (no reflow) [12]. In cardiac arrest patients, very early recurrence of VF during advanced life support is a well-known event. During pre-hospital care, just after resuscitation, around $75 \%$ of patients with VF as initial rhythm will develop at least one recurrence of $\mathrm{VF}(3,13)$. It has been shown that these re-fibrillation events are negatively associated with survival [13] and neurological recovery [14]. However, data regarding rhythmic complications that may occur later, during the ICU stay, are scarce. Incidence of rhythmic complications has mostly been studied in patients who presented an ACS without CA. For example, Ohlow et al [15] reported an incidence of malignant ventricular arrhythmia (VF or non-perfusing VT) of $4.7 \%$ in patients hospitalized for STEMI. In this cohort, 99\% of the patients had undergone a successful PCI. Examining the timing, $60 \%$ of these malignant ventricular events occurred within the first 24 hours and $92 \%$ within the first 48 hours after hospital admission. On the other hand, in a 293 non-STEMI cohort with successful revascularization, no patient presented serious arrhythmia recurrence (VF, VT, asystole) [16]. The results of our study suggest a clinically significant incidence of $11.3 \%$ of arrhythmia recurrences in our population of successfully revascularized patients. This incidence is higher than what is commonly reported in patients with of acute myocardial infarction $[15,17]$. This is plausible result since our patients have already presented a severe arrhythmia and a cardiac arrest and are therefore more likely to be at risk of recurrence. In addition, we decided that it was clinically relevant to consider atrial fibrillation requiring catecholamine as a severe arrhythmia. On the other hand, this incidence is quite low as compared with the immediate post-cardiac arrest period and transportation [3], suggesting that the risk decreased over time. Another explanation is the potential benefit of coronary revascularization, as previously discussed. 
We also found that $80 \%$ of major arrhythmia events occurred within the first 24 hours after ICU admission. This result is consistent with previous studies examining patients with acute myocardial

261

262

263

264

265

266

267

268

269

270

271

272

273

274

275

276

277

278

279

280

281

282

283

284

285

286

287

288

289

290

291

292 infarction [15]. This timing suggests that future prospective trials aiming to test the potential prophylactic benefit of AA should be done during the first hours of post cardiac arrest care. Importantly, among the 29 patients who had a major arrhythmia recurrence, only 4 had an obvious cause (stent thrombosis in all cases) for which a prophylactic AA treatment would possibly have no effect.

We have collected data on left ventricular systolic function at the admission because it is known that a low left ventricular dysfunction is associated with an increased risk for ventricular fibrillation in ischemic heart disease [18]. Our results are consistent since there was a greater proportion of patients with left ventricular dysfunction at admission in the major arrhythmia recurrence group. However, we did not show any association between left ventricular dysfunction and recurrence of major arrhythmia.

Dumas and al. showed that successful immediate percutaneous intervention was associated with improved hospital survival in patient with OHCA with no obvious extra-cardiac cause of arrest (7). In our study, there was a higher proportion of partial revascularization in the major arrhythmia group but no association between the degree of revascularization and the recurrence of arrhythmia was found in the multivariate analysis. However, the number of patients with a partially successful revascularization was too small to draw any firm conclusion.

No AA treatment has shown any effective prophylactic effect in patients resuscitated after CA. Some studies have highlighted the benefice of amiodarone or lidocaine in the prevention of rhythm disorder after acute myocardial infarction, but outside the context of cardiac arrest [19-25]. Only $\beta$ blockers are associated with a decrease of mortality after AMI, not only because of their anti-arrhythmic effect [26]. In the specific context of post-cardiac arrest care, only one retrospective study evaluated the benefice of prophylactic lidocaine treatment after a successful defibrillation in a large cohort of patients included between 1992 and 2008 [27]. In this study, the prevalence of re-arrests due to shockable arrhythmias was $21.8 \%$. This high incidence may be explained by the fact that patients were included just after the first ROSC, before hospital admission, and especially before coronary revascularization. Regarding prophylactic anti arrhythmic treatment, Kudenchuk et al. reported a lower incidence of recurrent cardiac arrest resulting from shockable arrhythmias in prophylactic lidocaine group as compared with placebo $(22.8 \%$ vs $38.5 \%, \mathrm{p}<0.0001)$. Nevertheless there is no firm recommendation about prophylactic use of antiarrhythmic drugs after ROSC in this population [4]. In brief, our results did not suggest a benefit in giving AA during the first days after a resuscitated $\mathrm{VF}$, but our study was underpowered and further prospective research is required to explore this aspect. 
The other clinically relevant result is the large difference in mortality rate between the two groups. Patients with major arrhythmia recurrence disorders had a significantly higher mortality rate than the expected mortality following a resuscitated CA with initial shockable rhythm [28]. This mortality rate was nearly $70 \%$ and reflects the severity of these patients. This is probably not solely due to the recurrence of major arrhythmia, since this recurrence is possibly a marker of severity associated with a more pejorative prognosis.

299

We acknowledge several limitations. First, some factors potentially responsible of major arrhythmia recurrence may have been missed. For example, patients who died from a new arrhythmia did not all have a new angiography to detect a potential stent thrombosis. The other confounding factor is the targeted temperature control since therapeutic hypothermia was performed in $90 \%$ of patients, a treatment that may provoke arrhythmia in this setting [29]. However, this bias was limited as the average of the minimum temperature during cooling was comparable between groups. In addition, the absence of a statistical link between major arrhythmia recurrence and the administration of prophylactic AA treatment is probably unreliable as this study was not designed to address this issue. The decision of AA treatment may simply reflect a higher perceived severity, based on arrhythmia recurrences during transportation or coronary angiogram. The small size of the prophylactic AA group leads to a lack of significant statistical power precluding any firm conclusion. Moreover, the purely descriptive design and the low number of patients who received prophylaxis preclude from any definitive conclusion regarding AA effect. Finally, the present study was performed in specific population of OHCA patients and results cannot be extrapolated to other populations. Indeed, in order to obtain a homogeneous population, we included only successful revascularization patients and we didn't use any control patients. As a consequence, our study is mainly descriptive and we cannot draw any firm conclusion regarding a protective effect of revascularization against early arrhythmic recurrences.

To conclude, recurrence of major arrhythmia is a frequent complication during the post resuscitation period, occurring mostly during the first 24 hours. Even if we did not find any association between prophylactic anti-arrhythmic treatment and risk of major arrhythmia recurrence, further research is required to clarify this point. 
[1] Berdowski J, Berg RA, Tijssen JGP, Koster RW. Global incidences of out-of-hospital cardiac arrest and survival rates: Systematic review of 67 prospective studies. Resuscitation 2010;81:1479-87. doi:10.1016/j.resuscitation.2010.08.006.

[2] Bougouin W, Lamhaut L, Marijon E, Jost D, Dumas F, Deye N, et al. Characteristics and prognosis of sudden cardiac death in Greater Paris: Population-based approach from the Paris Sudden Death Expertise Center (Paris-SDEC). Intensive Care Medicine 2014;40:846-54. doi:10.1007/s00134-014-3252-5.

[3] Koster RW, Walker RG, Chapman FW. Recurrent ventricular fibrillation during advanced life support care of patients with prehospital cardiac arrest. Resuscitation 2008;78:252-7. doi:10.1016/j.resuscitation.2008.03.231.

[4] Nolan JP, Soar J, Cariou A, Cronberg T, Moulaert VRM, Deakin CD, et al. European Resuscitation Council and European Society of Intensive Care Medicine Guidelines for Postresuscitation Care 2015. Resuscitation 2015;95:202-22. doi:10.1016/j.resuscitation.2015.07.018.

[5] Dargie HJ. Effect of carvedilol on outcome after myocardial infarction in patients with leftventricular dysfunction: the CAPRICORN randomised trial. Lancet 2001;357:1385-90.

[6] Cairns JA, Connolly SJ, Roberts R, Gent M. Randomised trial of outcome after myocardial infarction in patients with frequent or repetitive ventricular premature depolarisations: CAMIAT. Canadian Amiodarone Myocardial Infarction Arrhythmia Trial Investigators. Lancet 1997;349:675-82.

[7] Dumas F, Cariou A, Manzo-Silberman S, Grimaldi D, Vivien B, Rosencher J, et al. Immediate Percutaneous Coronary Intervention Is Associated With Better Survival After Out-of-Hospital Cardiac Arrest: Insights From the PROCAT (Parisian Region Out of Hospital Cardiac Arrest) Registry. Circulation: Cardiovascular Interventions 2010;3:200-7. doi:10.1161/CIRCINTERVENTIONS.109.913665.

[8] Cummins RO, Chamberlain D, Hazinski MF, Nadkarni V, Kloeck W, Kramer E, et al. Recommended guidelines for reviewing, reporting, and conducting research on in-hospital resuscitation: the in-hospital "Utstein style". American Heart Association. Circulation 1997;95:2213-39.

[9] Chelly J, Mongardon N, Dumas F, Varenne O, Spaulding C, Vignaux O, et al. Benefit of an early and systematic imaging procedure after cardiac arrest: Insights from the PROCAT (Parisian Region Out of Hospital Cardiac Arrest) registry. Resuscitation 2012;83:1444-50. doi:10.1016/j.resuscitation.2012.08.321.

[10] The Thrombolysis in Myocardial Infarction (TIMI) Trial. New England Journal of Medicine 1985;313:1018-1018. doi:10.1056/NEJM198510173131611.

[11] Kolettis TM. Coronary artery disease and ventricular tachyarrhythmia: pathophysiology and treatment. Current Opinion in Pharmacology 2013;13:210-7. doi:10.1016/j.coph.2013.01.001.

[12] Kolettis TM, Kontonika M, Valenti M-C, Vilaeti AD, Baltogiannis GG, Papalois A, et al. Arrhythmogenesis after acute myocardial necrosis with and without preceding ischemia in rats. Journal of Basic and Clinical Physiology and Pharmacology 2014;25. doi:10.1515/jbcpp-20130117.

[13] van Alem AP, Post J, Koster RW. VF recurrence: characteristics and patient outcome in out-ofhospital cardiac arrest. Resuscitation 2003;59:181-8. doi:10.1016/S0300-9572(03)00208-9.

[14] Berdowski J, ten Haaf M, Tijssen JGP, Chapman FW, Koster RW. Time in Recurrent Ventricular Fibrillation and Survival After Out-of-Hospital Cardiac Arrest. Circulation 2010;122:1101-8. doi:10.1161/CIRCULATIONAHA.110.958173.

[15] Ohlow M-A, Geller JC, Richter S, Farah A, Müller S, Fuhrmann JT, et al. Incidence and predictors of ventricular arrhythmias after ST-segment elevation myocardial infarction. The American Journal of Emergency Medicine 2012;30:580-6. doi:10.1016/j.ajem.2011.02.029.

[16] Wildi K, Cuculi F, Twerenbold R, Marxer T, Rubini Gimenez M, Reichlin T, et al. Incidence and timing of serious arrhythmias after early revascularization in non ST-elevation myocardial infarction. European Heart Journal: Acute Cardiovascular Care 2015;4:359-64. doi:10.1177/2048872614557230. 
[17] Bougouin W, Marijon E, Puymirat E, Defaye P, Celermajer DS, Le Heuzey J-Y, et al. Incidence of sudden cardiac death after ventricular fibrillation complicating acute myocardial infarction: a 5-year cause-of-death analysis of the FAST-MI 2005 registry. European Heart Journal 2014;35:116-22. doi:10.1093/eurheartj/eht453.

[18] Solomon SD, Zelenkofske S, McMurray JJV, Finn PV, Velazquez E, Ertl G, et al. Sudden Death in Patients with Myocardial Infarction and Left Ventricular Dysfunction, Heart Failure, or Both. New England Journal of Medicine 2005;352:2581-8. doi:10.1056/NEJMoa043938.

[19] Effect of prophylactic amiodarone on mortality after acute myocardial infarction and in congestive heart failure: meta-analysis of individual data from 6500 patients in randomised trials. Amiodarone Trials Meta-Analysis Investigators. Lancet 1997;350:1417-24.

[20] Lie KI, Liem KL, Louridtz WJ, Janse MJ, Willebrands AF, Durrer D. Efficacy of lidocaine in preventing primary ventricular fibrillation within 1 hour after a $300 \mathrm{mg}$ intramuscular injection. A double-blind, randomized study of 300 hospitalized patients with acute myocardial infarction. Am J Cardiol 1978;42:486-8.

[21] Lie KI, Wellens HJ, van Capelle FJ, Durrer D. Lidocaine in the prevention of primary ventricular fibrillation. A double-blind, randomized study of 212 consecutive patients. N Engl J Med 1974;291:1324-6. doi:10.1056/NEJM197412192912504.

[22] Koster RW, Dunning AJ. Intramuscular Lidocaine for Prevention of Lethal Arrhythmias in the Prehospitalization Phase of Acute Myocardial Infarction. New England Journal of Medicine 1985;313:1105-10. doi:10.1056/NEJM198510313131801.

[23] Sadowski ZP, Alexander JH, Skrabucha B, Dyduszynski A, Kuch J, Nartowicz E, et al. Multicenter randomized trial and a systematic overview of lidocaine in acute myocardial infarction. American Heart Journal 1999;137:792-8. doi:10.1016/S0002-8703(99)70401-1.

[24] Alexander JH, Granger CB, Sadowski Z, Aylward PE, White HD, Thompson TD, et al. Prophylactic lidocaine use in acute myocardial infarction: Incidence and outcomes from two international trials. American Heart Journal 1999;137:799-805. doi:10.1016/S00028703(99)70402-3.

[25] Martí-Carvajal AJ, Simancas-Racines D, Anand V, Bangdiwala S. Prophylactic lidocaine for myocardial infarction. In: The Cochrane Collaboration, editor. Cochrane Database of Systematic Reviews, Chichester, UK: John Wiley \& Sons, Ltd; 2015.

[26] Freemantle N, Cleland J, Young P, Mason J, Harrison J. beta Blockade after myocardial infarction: systematic review and meta regression analysis. BMJ 1999;318:1730-7. doi:10.1136/bmj.318.7200.1730.

[27] Kudenchuk PJ, Newell C, White L, Fahrenbruch C, Rea T, Eisenberg M. Prophylactic lidocaine for post resuscitation care of patients with out-of-hospital ventricular fibrillation cardiac arrest. Resuscitation 2013;84:1512-8. doi:10.1016/j.resuscitation.2013.05.022.

[28] Casey E, Marsh B. Outcomes following admission to ICU post cardiac arrest. Critical Care 2009;13:P64. doi:10.1186/cc7228.

[29] Salinas P. Electrocardiographic changes during induced therapeutic hypothermia in comatose survivors after cardiac arrest. World Journal of Cardiology 2015;7:423. doi:10.4330/wjc.v7.i7.423. 


\section{Figures.}

$428 \quad$ Figure 1. Flow chart

429 Abbreviations: VF: ventricular fibrillation, VT: ventricular fibrillation, ACS: acute coronary 430 syndrome, ICU: intensive care unit, AA: anti arrhythmic.

431

Tables.

\section{$433 \quad$ Table 1. Baseline characteristics}

434 Abbreviations: $\mathrm{CA}=$ cardiac arrest; $\mathrm{CPR}=$ cardio-pulmonary resuscitation; $\mathrm{AA}=$ anti-arrhythmic; 435 ICU = intensive care unit; ECG = electrocardiogram; $\mathrm{PCI}=$ percutaneous coronary intervention; LVEF $436=$ left ventricular ejection fraction.

\section{Table 2. Characteristics of ECG and coronary angiogram}

438 Abbreviations: $\mathrm{ECG}=$ electrocardiography; TIMI= thrombolysis in myocardial infarction; $\mathrm{LVEF}=$ left 439 ventricular ejection fraction; ICU= intensive care unit.

440 Table 3. Factors associated with major arrhythmia (auricular or ventricular) recurrence in

$441 \quad$ multivariate analysis

442 Abbreviations: $\mathrm{CPR}=$ cardio-pulmonary resuscitation; $\mathrm{AA}=$ anti-arrhythmic; $\mathrm{ICU}=$ intensive care unit;

$443 \mathrm{LVEF}=$ left ventricular ejection fraction; TIMI= thrombolysis in myocardial infarction.

444

445

446

447

448

449

450

451

452

453

454 


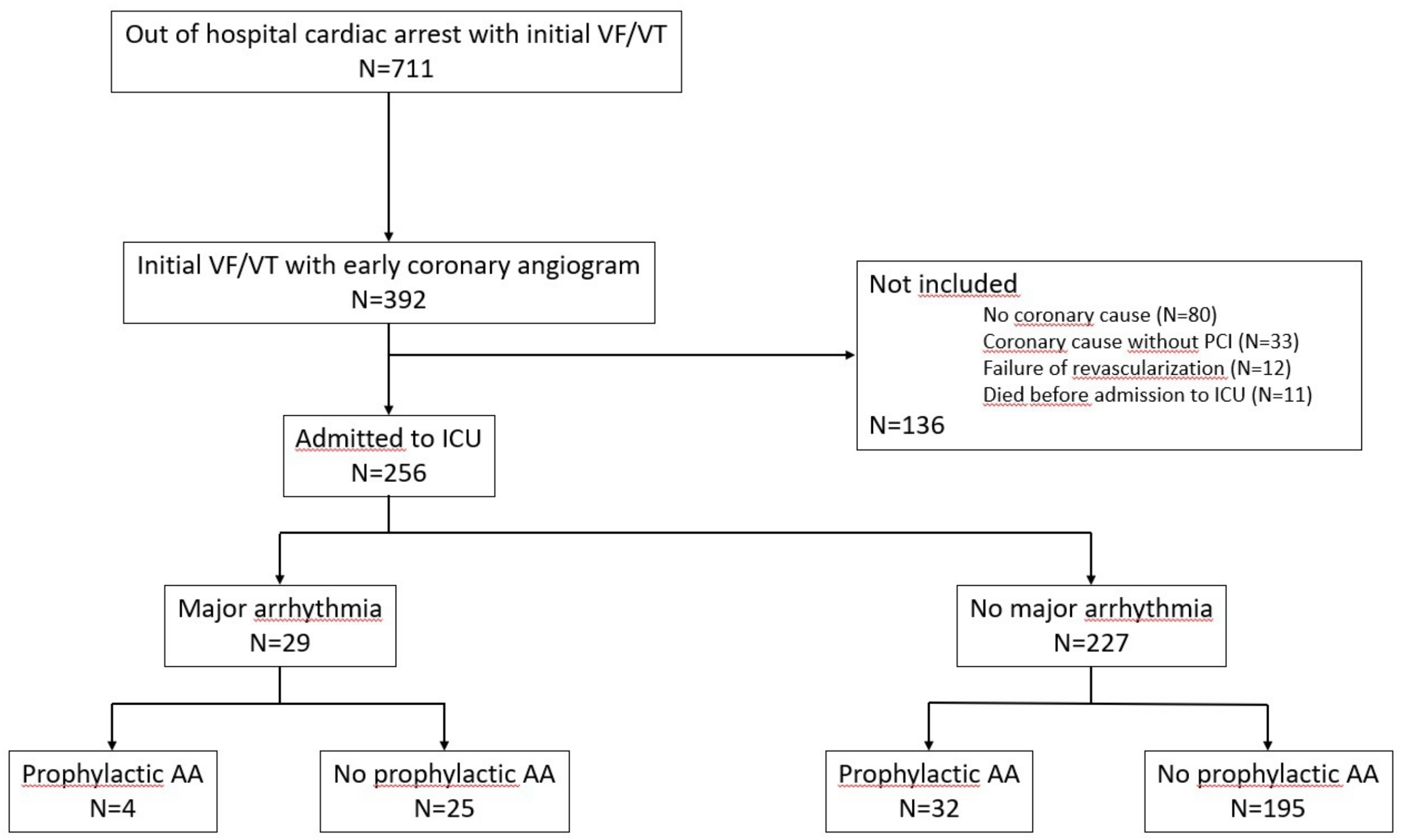




\begin{tabular}{|c|c|c|c|c|}
\hline & $\begin{array}{l}\text { Overall } \\
N=256\end{array}$ & $\begin{array}{c}\text { No major } \\
\text { arrhythmia } \\
N=227\end{array}$ & $\begin{array}{c}\text { Major } \\
\text { arrhythmia } \\
N=29\end{array}$ & $\begin{array}{c}p- \\
\text { value }\end{array}$ \\
\hline Age $>59$ years; $n(\%)$ & $130(51)$ & $114(50)$ & $16(55)$ & 0.62 \\
\hline Male gender; $n(\%)$ & $205(80)$ & $185(82)$ & $20(69)$ & 0.14 \\
\hline Hypertension; $n(\%)$ & $96(39)$ & $81(37)$ & $15(53)$ & 0.09 \\
\hline Diabetes; $n(\%)$ & $39(16)$ & $35(16)$ & $4(14)$ & 1 \\
\hline Dyslipidemia; $n(\%)$ & $83(34)$ & $74(34)$ & $9(32)$ & 0.85 \\
\hline Smoking; $n(\%)$ & $170(72)$ & $146(70)$ & $24(89)$ & 0.04 \\
\hline Coronary disease; $n(\%)$ & $35(14)$ & $32(14)$ & $3(11)$ & 0.78 \\
\hline Public place; $n(\%)$ & $124(48)$ & $117(51)$ & $7(24)$ & 0.006 \\
\hline Witnessed $C A ; n(\%)$ & $246(97)$ & $218(97)$ & $28(97)$ & 1 \\
\hline Bystander CPR; $n(\%)$ & $180(72)$ & $158(71)$ & $22(76)$ & 0.62 \\
\hline Number of defibrillation $>2 ; n(\%)$ & $117(46)$ & $101(45)$ & $16(57)$ & 0.23 \\
\hline Time between collapse and ROSC >20 min; $n(\%)$ & $117(48)$ & $102(47)$ & $15(56)$ & 0.40 \\
\hline Epinephrine > Img during CPR; $n(\%)$ & $106(43)$ & $90(41)$ & $16(59)$ & 0.08 \\
\hline Amiodarone during $C P R ; n(\%)$ & $104(41)$ & $87(39)$ & $17(59)$ & 0.07 \\
\hline Prophylactic AA treatment in the ICU; $n(\%)$ & $36(14)$ & $32(14)$ & $4(14)$ & 1 \\
\hline Lactate $>3.65 \mathrm{mmol} / \mathrm{L} ; n(\%)$ & 111(65) & $94(48)$ & $17(65)$ & 0.14 \\
\hline Post-resuscitation hemodynamic shock; $n(\%)$ & $133(52)$ & $116(51)$ & $17(59)$ & 0.56 \\
\hline Dobutamine and/or epinephrine in ICU; $n(\%)$ & $144(56)$ & $125(55)$ & $19(66)$ & 0.33 \\
\hline Lowest temperature during first 24 hours; average ${ }^{\circ} \mathrm{C}(S D)$ & $32.71(1.23)$ & $32.75(1.17)$ & $32.35(1.64)$ & 0.12 \\
\hline Mortality rate (all cause); $n(\%)$ & $114(45)$ & $94(41)$ & $20(69)$ & 0.006 \\
\hline
\end{tabular}


Table 2. Characteristics of ECG and coronary angiogram

\begin{tabular}{|c|c|c|c|c|}
\hline & $\begin{array}{l}\text { Overall } \\
N=256\end{array}$ & $\begin{array}{c}\text { No major } \\
\text { arrhythmia } \\
N=227\end{array}$ & $\begin{array}{c}\text { Major } \\
\text { arrhythmia } \\
N=29\end{array}$ & $\begin{array}{c}p- \\
\text { value }\end{array}$ \\
\hline $\begin{array}{l}\text { ST-segment elevation on post-resuscitation ECG; } n \\
(\%)\end{array}$ & $100(39)$ & $85(37)$ & $15(52)$ & 0.15 \\
\hline Coronary artery lesions; $n(\%)$ & & & & 0.20 \\
\hline one-vessel disease & $115(45)$ & $105(46)$ & $10(34)$ & \\
\hline double-vessel disease & $78(30)$ & $70(31)$ & $8(28)$ & \\
\hline triple-vessel disease & $63(25)$ & $52(23)$ & $11(38)$ & \\
\hline TIMI score; $n(\%)$ & & & & 0.048 \\
\hline TIMI 3 & $233(91)$ & $209(92)$ & $24(83)$ & \\
\hline TIMI 2 & $20(8)$ & $15(7)$ & $5(17)$ & \\
\hline LVEF at ICU admission; $n(\%)$ & & & & 0.03 \\
\hline$<50 \%$ & $170(66)$ & $146(64)$ & $24(83)$ & \\
\hline$\geq 50 \%$ & $69(27)$ & $66(29)$ & $3(10)$ & \\
\hline
\end{tabular}

Table 3. Factors associated with major arrhythmia (auricular or ventricular) recurrence in multivariate analysis

\begin{tabular}{l|cccc}
\multicolumn{1}{c}{} & OR & [95\% Conf. & Interval] & p-value \\
\hline Age $>$ 59 years & 2.27 & 0.81 & 6.37 & 0.12 \\
Male gender & 0.32 & 0.12 & 0.92 & 0.034 \\
Number of defibrillation attempts $>2$ & 1.57 & 0.54 & 4.53 & 0.4 \\
Epinephrine $>$ Img during CPR & 1.12 & 0.35 & 3.56 & 0.85 \\
Amiodarone during CPR & 2.19 & 0.74 & 6.15 & 0.16 \\
Prophylactic AA treatment in the ICU & 0.85 & 0.21 & 3.65 & 0.82 \\
Lactate $>3.65 m m o l / L$ & 1.41 & 0.45 & 4.39 & 0.56 \\
LVEF $\geq 50 \%$ at admission & 0.42 & 0.11 & 1.43 & 0.19 \\
TIMI score 3 & 0.59 & 0.16 & 2.14 & 0.42
\end{tabular}

